\title{
Chemicals in the water environment. Where do the real and future threats lie?
}

\author{
John Fawell \\ Water Institute, Cranfield University, Cranfield, United Kingdom
}

\begin{abstract}
There are many potential sources of chemical constituents and contaminants in water that can reach drinking water. Not all substances will be present in any particular water. Some substances may be of benefit to health but others can be a threat. However, very few have been clearly shown to cause adverse health effects in humans through drinking water and evidence may be complicated by simultaneous exposure through food. Our knowledge of contaminants in water is, however, incomplete as additional contaminants emerge with advancing analytical methods. Most of these emerging contaminants are present as a consequence of day to day use by the wider human population and control requires a different approach to the substance by substance regulation prevalent at present.
\end{abstract}

Key words: drinking water, chemicals, pollution, health.

Riassunto (Sostanze chimiche nell'ambiente acquatico. Quali sono le minacce attuali e future?). Sono molte le fonti potenziali di costituenti e contaminanti chimici nell'acqua che possono raggiungere le acque potabili. Non tutte le sostanze sono presenti in ogni acqua, alcune possono giovare alla salute ma altre possono rappresentare una minaccia. Tuttavia, solo per un numero limitato di sostanze è stata chiaramente dimostrata una relazione causale per effetti avversi sulla salute associata al consumo di acqua potabile e le evidenze sono rese complicate dalla simultanea esposizione attraverso gli alimenti. La conoscenza dei contaminanti nelle acque è comunque incompleta poiché nuovi contaminanti emergono con lo sviluppo di metodi analitici avanzati. Gran parte di questi contaminanti è presente come conseguenza dell'uso quotidiano da parte di una popolazione crescente e i controlli richiedono un approccio regolatorio diverso da quello attuale basato sulle singole sostanze.

Parole chiave: acque potabili, sostanze chimiche, contaminazione, salute.

\section{INTRODUCTION}

We have discovered over time that many chemicals reach water, whether it is groundwater, rivers, lakes, estuaries or oceans. These chemicals may be highly water soluble through the whole range of solubility to virtually insoluble and they come from natural sources, from industry, human habitation and from agriculture. The sources can be point sources or diffuse sources reaching water through run-off from land or diffusion into groundwater. As our analytical capabilities have increased we can detect ever smaller amounts of chemicals and the sheer volume of information makes it difficult to determine what is important and what is not. Some chemicals, such as nutrients, have indirect effects causing blooms of algae that can have a range of impacts on aquatic ecosystems and on users of the water, or those who exploit those ecosystems. While we have learnt a great deal, our knowledge is imperfect and problems that arise are frequently localized so the issues for one water body can be very different from the issues for another.

Many chemical substances have been known to be water contaminants for many years but, for some, controls to reduce and eventually eliminate their use have been agreed and implemented, although some may be present in the environment long after we cease to use them. Some are naturally occurring and these are the ones we know do cause adverse human health effects when present at sufficiently high concentrations. Water contaminants are both inorganic and organic with the latter comprising many thousands of substances that can be possibly present in water. As indicated above the range of substances in any individual water body will vary significantly and only a small proportion of the possible contaminants will be present. Those that are may not always be present and they will usually vary in concentration at different times, sometimes significantly. When assessing the possible risks to health of water contaminants it is also important to consider exposure from other sources since drinking water is often a minor source and epidemiological studies looking just at drinking water may give highly misleading results.

Direct impacts on human health can be either through drinking water or through contamination of aquatic organisms eaten by humans. In this lat- 
ter case there is the potential for accumulation over time so that unexpectedly high amounts may be present. However, for drinking water there is often water treatment which can also vary in sophistication and effectiveness against both inorganic and organic substances. Generally the most extensive treatment will be installed on large municipal supplies taking water from surface waters that have the potential to be impacted by a wide range of pollutant sources. In addition, as water resources come under pressure from increasing demand, sources of water that would not have been considered in the past such as recycled wastewater and saline waters are being used for drinking water either directly or indirectly by augmenting traditional supplies and sources after suitable treatment.

\section{NATURAL CONTAMINANTS}

There are both inorganic and organic contaminants that arise naturally. Drinking water can contain many minerals, often in very small concentrations, that come from contact with the rocks and soils through and over which it passes. Most of these are of no concern and some, such as calcium and magnesium, may even be beneficial [1]. In addition there are substances that are essential for health, such as copper, selenium, manganese and chromium, which may also be toxic at higher intakes. For such substances any risk assessment regarding health effects must balance essentiality and possible toxicity. However, some are known to impact human health as a consequence of their presence in water. The two most important in this respect are arsenic and fluoride that are present in groundwater in many parts of the world [2]. They are a particular problem in small rural supplies for which resources are very limited and treatment may not be a practical solution. They are particularly important in areas where the water is used to irrigate rice, which takes up contaminants more than many other food crops, as shown by the accumulation of cadmium in the Toyama Prefecture in Japan which gave rise to itai itai disease [3]. Both arsenic and fluoride are significant contributors to morbidity in regions where concentrations in water are high. Arsenic causes skin and peripheral vascular disease and a variety of cancers while fluoride causes crippling bone disease $[4,5]$. In the developed counties of the west they are of relatively minor importance because of the resources available to provide treatment, even at a household level for very small supplies.

There are other inorganic substances that are naturally occurring, such as selenium [6] and uranium [7], which have raised concerns. While some epidemiological studies have found both beneficial and adverse associations with exposure to selenium, which is an essential element, these studies do not take into account overall exposure and most of the adverse effects have been seen in areas where there are highly seleniferous soils and high selenium in crops. In Western
Europe the greatest problem seems to be a potential for selenium intake from all sources to be too low. Uranium occurs naturally in groundwater sources in many parts of the world and the problems mainly relate to small supplies where resources are limited. Animal studies were used to derive a guideline value for drinking water by WHO but subsequent epidemiological studies, on populations exposed to much greater concentrations of uranium in water over long periods, did not provide any support for the guideline value. As a consequence the guideline value has been raised but there still remains uncertainty as to whether this is too conservative [7]. Occasional animal studies appear to show adverse effects at low concentrations but these are not consistent and the evidence from humans remains largely reassuring.

There are also naturally occurring organic contaminants that are important. Humic and fulvic acids are present as a consequence of the breakdown of plant material and are large complex molecules. Although these are not of significance on their own they are the precursors of unwanted disinfection by-products that are considered below under contaminants that arise from water treatment. Other organic substances that are directly of concern for health are toxins produced by algae in fresh and marine waters. These algae form large blooms often as a consequence of nutrients discharged into surface fresh waters and coastal waters. The key nutrients are phosphate in fresh water and nitrate in marine water. In fresh water a number of cyanobacterial species produce toxins, which include the microcystins and cylindrospermopsin that are hepatotoxins, and anatoxin $\mathrm{A}$ and AS that are neurotoxins. Some blooms also produce saxitoxin which is also a product of some marine dinoflagellates and causes paralytic shellfish poisoning (PSP). While the evidence of health problems from drinking water are limited to areas where blooms occur in water supplies that do not receive other than basic treatment, they can impact on livestock and pets that drink from the untreated water bodies. Although treatment can remove the toxins, preventing blooms forming is always a first line of defence [8].

The toxins which are a product of marine dinoflagellate blooms are an important cause of adverse human health effects from the consumption of shellfish that accumulate the dinoflagellate phytoplankton [9]. In many parts of the world governments have established routine screening of shell fisheries to prevent populations being exposed.

\section{CONTAMINANTS FROM AGRICULTURE}

Agriculture is one of the sources of nutrients that reach surface waters and, in the case of nitrate, groundwater that is vulnerable to leaching from the surface. The greatest concerns have been directed at nitrate contamination, particularly of groundwater, although new evidence means that there are significant uncertainties regarding potential effects. For 
many years it was believed that nitrate was the main cause of methaemoglobinaemia in bottle-fed infants with concentrations of nitrate above $50 \mathrm{mg} /$ litre as nitrate, the risk increasing with increasing concentration. However, increasing evidence shows that diarrhoeal disease itself significantly increases methaemoglobin formation in infants and in the absence of existing infections much higher concentrations of nitrate are required. WHO recommends that water with greater than $100 \mathrm{mg} /$ litre of nitrate should not be used but that water with between 50 and $100 \mathrm{mg} / \mathrm{li}$ tre can be used if it is microbiologically safe and there is increased vigilance for methaemoglobinaemia [2]. The evidence for cancer resulting from high nitrate intake through drinking water also remains equivocal at best but there is evidence that the capacity of nitrate for interfering with iodine uptake may be of greater significance. To date the evidence remains weak and certainly insufficient to identify concentrations of concern but there is a need to carry out high quality epidemiological studies to answer this question [10]. There is also increasing evidence that nitrate may have beneficial effects through the nitric oxide cycle in the body and there is endogenous formation of both nitrate and nitrite [11].

The other chemical contaminants of greatest concern with regard to agriculture are pesticides of various types. The majority of pesticides are not routinely found in water and, with the exception of spills in which the level of contamination is unusually high, the concentrations do not appear to be of significance for human health in most places, although there may be issues for some small nonmunicipal supplies in rural areas. In the EU, the introduction of the blanket standard for any pesticide in drinking water of $0.1 \mu \mathrm{g} /$ litre has meant that concentrations in European drinking water are well below concentrations of concern for health. In addition there is no credible evidence for adverse health effects from pesticides through drinking water. The most toxic pesticides are of very low water solubility and so are not found at significant concentrations in water. WHO has developed conservative healthbased guidelines for a number of pesticides in relation to drinking water against which observed concentrations can be compared [2]. Such guidelines are particularly useful when spills occur and drinking water is threatened over a short time as well as when there is the potential for chronic exposure since mere presence does not equate with the threat of adverse health effects if concentrations are low.

\section{INDUSTRY AND HUMAN HABITATION}

A very wide variety of chemicals may reach water from industry in industrial discharges and from the careless handling of chemicals, the most common of which are hydrocarbons from petroleum products. These latter substances are largely detected in drinking water by odour at concentrations below those of concern for health [2]. As legislation and controls on surface water contamination have been introduced, these chemicals have become less and less of an issue. In the past the discharge of heavy metals was a concern and in some developing countries it still is. However, adverse health effects from metals have not usually been directly associated with drinking water but through accumulation in crops, such as rice, e.g. Itai Itai disease in Japan from accumulated cadmium [3], or aquatic organisms, such as methyl mercury in aquatic life in Minimata Bay in Japan. Indeed mercury in the form of methyl mercury remains a threat to some populations that eat a mostly fish-based diet [12].

There are also concerns about highly lipophilic substances such as the polychlorinated biphenyls and polybrominated diphenyl ethers (PCBs and PBDEs) that were used in electrical equipment and as flame retardants respectively. These are controlled as persistent organic pollutants (POPs) through international conventions. They are of no consequence for treated drinking water but they have been found widely in aquatic life around the globe. In spite of the controls in place, they will be present in the environment for an extremely long time and remain a concern. While there are uncertainties regarding the extent to which they pose a threat to human health specifically through consumption of aquatic organisms minimising exposure does remain a priority $[13,14]$. Unless great care is taken in finding alternative chemicals for use as fire retardants more problem chemicals will appear in the future.

More recently other persistent chemicals have emerged as potential problems for drinking water; the perfluorinated compounds such as PFOS and PFOA (perfluorooctane sulfonic acid and perfluorooctanoic acid). These substances were used as the building blocks for dirt resistant coatings on fabrics and non-stick coatings on cookware but they were also used in detergents that were widely included in fire-fighting foams, particularly for fighting aircraft fires. Although these substances are persistent in the environment, they are highly soluble and can readily reach unprotected groundwater. They are seen at elevated concentration in groundwater near manufacturing facilities but also near airports where there are practice areas for fire-fighting. Again action has now been taken to strictly control their use but the legacy will remain for some time. These substances are of concern for health but there remain uncertainties in the toxicology that are to be fully resolved. In the meantime research on exposed populations is being carried out to monitor health for a possible range of adverse effects $[15,16]$.

Another group of chemicals that have been frequently identified in groundwater, but not surface water, are the chlorinated solvents that were widely used for degreasing and dry cleaning in the past. Controls over handling and disposal have significantly reduced the risk of these substances polluting groundwater in the future but this may not be the case in many developing countries. Once in ground- 
water they may be present for a significant period of time and some instances of contamination date back to the second world war. Other related substances are tetrachloroethene used in dry cleaning and more recently, 1,1,1-trichloroethane that was used as a less toxic replacement for the others. Where contamination has been found, particularly in the United States, there have been attempts to determine whether there have been adverse health effects through epidemiological studies. However, the concentrations are generally low and the results remain equivocal [2].

\section{EMERGING CONTAMINANTS}

With advances in analytical capability we are able to detect an increasing number of substances in water at ever lower concentrations. As a consequence our knowledge of water contaminants is increasing. These emerging contaminants will, in many cases, have been present for a long time and most are present as a consequence of domestic use, although some are quite natural, such as the hormones that are excreted by humans and animals. The primary, but not exclusive, route to water for these substances is through sewage and their presence in wastewater discharges. One group that can reach groundwater directly under areas of use is the perfluorinated compounds mentioned above but in developing countries there are cases of significant concentrations of pharmaceuticals in discharges from factories making generic compounds. While there are specific circumstances where exposure may be significantly elevated, the current discussion will relate to regions where there are controls over discharges that are enforced and where there is both wastewater treatment and drinking water treatment. The substances of interest are endocrine disruptors, classified by their potential biological activity, personal care products, which is a wide ranging group containing substances from cleaning and washing through personal hygiene products and cosmetics, and pharmaceuticals, which is another wide ranging group in terms of structures and activity.

Endocrine Disrupters are substances that are capable of mimicking or interfering with the hormonal system. Questions were first raised in the early 1980's [17] but it was when male fish living downstream from treated sewage effluent discharges were found to have ovarian elements in their testis that there was concern. It was shown that the primary cause was natural and artificial hormones excreted by humans as the glucuronides and sulphates to make them soluble. However, the conjugates are broken down in sewage treatment to rerelease the parent compounds that are active and the effect rapidly disappears further downstream as the substances are adsorbed to organic material. Other chemicals also shown to have this effect were much less potent than the hormones but alkyl phenols used as detergent builders were also shown to impact fish at specific locations. Since then the alkyl phenols have been phased out. Because of the impact on fish there has been concern over the possible threat to drinking water. However, these substances are hydrophobic and are readily removed from water, which has been shown in various studies [18] and particularly by a significant study for the European Commission [19]. As a consequence the risks from drinking water where there is both sewage treatment and adequate water treatment are minimal.

Pharmaceuticals were first identified in drinking water in the early 1980's but since then there has been a significant increase in analytical capability that has shown an explosive increase in the number of pharmaceuticals and their residues detected in sources used for drinking water. All of these sources are impacted by municipal sewage effluent and the primary source in these is excretion by humans taking medication, although a small proportion comes from improper disposal of unused pharmaceuticals to sewer. There may be hot spots for discharges of specific pharmaceuticals, such as some hospitals, clinics and homes for the elderly and in developing countries uncontrolled discharges from factories making generic pharmaceuticals. A proportion of pharmaceuticals are removed in wastewater treatment and there is further degradation in surface water. Drinking water treatment will also remove a significant proportion, depending on the sophistication of the treatment and the concentration of pharmaceuticals present in the raw water. Occasionally specific pharmaceuticals may be found in groundwater from past improper disposal of pharmaceuticals by burial or to older unsealed landfill, however, this is rare, not least because of the high value of most pharmaceuticals. Several studies have examined the issues surrounding pharmaceuticals in drinking water and WHO established an expert committee which reported in 2011 [20-22]. These studies demonstrated that pharmaceuticals are present at very low concentrations, generally less than $0.1 \mu \mathrm{g} /$ litre in water sources. Very few are found in drinking water and those that are, such as ibuprofen, naproxen, carbamazepine, benzoylecgonine and caffeine, are found at even lower concentrations, generally below $0.05 \mu \mathrm{g} /$ litre $[22,23]$. WHO has considered all of the risk assessments and has concluded that the risks to health are, at present, minimal since the concentrations present are many orders of magnitude below the lowest therapeutic doses. However, it is not possible to provide definitive reassurance for the long-term as the concentrations and numbers of substances present will change with time and there remain uncertainties regarding groups that may be particularly vulnerable, such as bottlefed infants. In addition the question of personal care products used in toiletries and in household products such as cleaning agents remains to be 
properly investigated. Since the primary source is human use and discharge through municipal wastewater treatment there is an urgent need to begin the process of improving municipal wastewater treatment to remove these and other contaminants that will emerge in the future. This treatment will need to be sustainable and not increase carbon footprint. It will also have to be introduced over a long period in view of the significant investment required and the long life of such assets [24]. This approach also means that any threat to aquatic life will also be mitigated and so must be seen as the most sustainable approach, which also fits with the Water Safety Plan approach to assuring drinking water safety introduced by WHO in the third and fourth editions of the guidelines for drinking water quality.

\section{CHEMICALS ARISING FROM DRINKING WATER TREATMENT}

While drinking water treatment and distribution is vital in protecting public health against microbial illness which remains a major cause of morbidity and mortality in many parts of the world, care has to be taken that treatment does not introduce higher levels of unwanted by-products than necessary. Such disinfection by-products (DBPs) arise from a number of sources but the best studied are those that result from the reaction between natural organic matter in water sources and chlorine used as a disinfectant. Those present at the highest concentration are the trihalomethanes that are regulated in most parts of the world and the haloacetic acids that are regulated in North America and for which guidelines have been set by WHO [2]. These molecules may also contain bromine and iodine, depending on the presence of these naturally occurring inorganic contaminants in water. There are many other chlorination by-products and they have been the subject of study over several decades since they were first discovered. However, the introduction of regulations has resulted in a significant decline in concentrations, particularly with the introduction of improved treatment to remove the natural organic matter and better filtration that means less chlorine needs to be added. Improvements in the distribution system also mean that re-chlorination as a palliative against microbial contamination in distribution is less and less common. Epidemiological studies reported weak associations between chlorination and cancers of the colon, rectum and bladder. As better exposure data were introduced, only bladder remained positive in some studies but not others. The association remains weak and currently there is no plausible mechanism for this. However, the identification of low concentrations of a range of nitrogen containing DBPs may change this, if the data can be used for epidemiological studies taking into account the changes in concentrations over the past 20 years as efforts have been made to control DBPs. WHO concluded that the data did not allow a conclusion that the association was causal $[2,25]$.

Several studies also reported positive associations between THM concentrations and a number of adverse reproductive effects, particularly stillbirth and low weight for gestational age [25, 26]. However, as better studies were carried out these were increasingly negative and evidence started to emerge of confounding factors. The position is now that although there is a small theoretical risk from chlorination by-products the benefits from chlorination are significant and demonstrable and chlorination continues to be practiced in most parts of the world. WHO have made it clear that although disinfection by-products should be minimized where possible, microbiological safety should never be compromised in meeting guidelines and standards for chlorination by-products [2].

Other substances arise from the treatment process, particularly aluminium where aluminium salts are used as coagulants to remove organic matter and particles, including microorganisms. Concern was expressed about the possible link between aluminium in drinking water and Alzheimer's disease following the demonstration that aluminium in dialysate was responsible for dialysis dementia in patients on kidney dialysis. Although a number of epidemiological studies reported a positive association others were negative. Further studies showed that the bioavailability from water was low and the position remained equivocal at worst. JECFA reviewed the data on aluminium from all sources and concluded that at the concentrations found in drinking water a causal association was unlikely and proposed a provisional tolerable weekly intake of $1 \mathrm{mg} / \mathrm{kg}$ of bodyweight which would translate into a drinking water value of $0.9 \mathrm{mg} /$ litre assuming that $20 \%$ of the intake was allocated to drinking water, which would be conservative [27]. However, excess aluminium from treatment that is not properly optimized gives rise to the deposition of aluminium hydroxide flocs in distribution and these can cause significant problems with acceptability if disturbed. The standard of $200 \mu \mathrm{g} /$ litre in the European Directive is quite high and larger well run treatment works should be able to achieve average concentrations of well below $100 \mu \mathrm{g} /$ litre [2].

\section{MATERIALS USED IN PIPEWORK}

The most important contaminants from pipework used in water supply are lead and copper, which are found in the plumbing of buildings and also for connections between the public distribution system and the point at which water enters the building. Lead was used extensively for many decades as was leaded solder and a number of lead containing alloys. There are several factors that affect the dissolution of lead so that concentrations will vary 
from building to building and sometimes even tap to tap. Concentrations are usually higher following extended periods during which the water is in contact with the pipes and so concentrations are often highest in first draw water in the morning but also first draw after any longer standing period. Action has been taken to reduce lead levels in drinking water as well as lead from other sources because lead is a neurotoxin and can adversely affect IQ in children and also blood pressure in adults. There is little doubt that lead in water contributed significantly to lead uptake and that there was a pressing need to reduce exposure. However, the contribution of drinking water is confounded by the contribution from other sources, particularly dust and food. The current debate is whether current low blood lead levels in children (about $2 \mu \mathrm{g} / \mathrm{dl}$ ) are of significance and need to be further lowered. CDC in the United States has proposed altering the action level for blood lead in children to $5 \mu \mathrm{g} / \mathrm{dl}$ [28]. Much depends on the source but continued efforts to reduce lead exposure from sources such as old lead paint in older buildings are important. Whether lead in drinking water that meets the WHO guideline value of $10 \mu \mathrm{g} /$ litre is a significant source of lead remains uncertain but removing lead pipes from within domestic properties is difficult and householders need to be convinced that the cost and disturbance are worthwhile. However, there are steps that can be taken to reduce lead exposure in children, such as flushing the tap and pipework after periods of standing and also removal of lead pipe and lead containing fittings in buildings where children will be exposed and where there will be frequent periods of stagnation, such as schools. These variations in exposure make determining which sources of exposure are most important very difficult and so specific research is complex, particularly since at low blood lead levels the effects will be very small and IQ is impacted by a wide range of other factors.

Copper is very different from lead and occasionally is still the cause of health effects in consumers. However, the effects are acute, reversible and relate to the concentration in the water rather than the intake over time. Copper is a gastric irritant and can cause nausea and, if concentrations are sufficiently high, vomiting [29]. Higher concentrations can occur in new copper pipe that has been left in contact with aggressive water, particularly for extended periods such as is found in new buildings or after a week-end in which the building is not used. It was also suggested that copper could be responsible for some forms of childhood cirrhosis of the liver but data no longer support that this is due to normal copper levels in drinking water [30].

\section{DISCUSSION}

Chemicals that may be present in drinking water have received increasing attention over the past 30 years, even where there is little evidence to show that they are of concern. The benefit that has accrued from this increasing awareness has been that steps have been taken to minimize the concentrations of many of these substances and particularly the few that have been shown to cause health effects through drinking water. However, as knowledge increases and as new substances may reach drinking water it is important that the potential for health effects is properly assessed and, where necessary, proper steps should be taken to mitigate any significant risks.

The substances that have been clearly shown to impact on human health through drinking water are arsenic, fluoride and, to a lesser extent nitrate and lead. It is notable that these are all inorganic substances and the major issues almost invariably relate to small supplies where the resources available are limited. Many people around the world, including Europe, receive their water from such supplies so effort needs to be directed to assuring their safety. Doubtless new potential problems will emerge and these will need to be investigated but it is important that the risks associated with chemical constituents and contaminants in drinking water are not over stated to the detriment of vigilance regarding microbiological pathogens.

Chemicals that are less of a problem for drinking water may still pose a risk to health through the consumption of contaminated staples in the diet. Metals are of particular concern in this respect through consumption of both fish and shellfish but also consumption of rice that is irrigated with contaminated water, with arsenic, cadmium and fluoride being of particular concern.

Chemicals have brought many benefits to our society and in developed countries, at least, we continue to live longer and healthier lives than ever before. While many of the environmental impacts on health relate to self-inflicted lifestyle factors, which are probably the greatest influence, chemicals that we use do have the potential to cause problems which are avoidable. The best way of dealing with these problems is prevention and to achieve this we will need to take decisions that relate to long-term change to anticipate potential future threats. To do this will require a new look at wastewater treatment and urban run-off with a view to preventing contaminants reaching the aquatic environment. Dealing with problems by a chemical by chemical approach after the event that we still tend to follow will not deliver the benefits that come from prevention of pollution.

\section{Conflict of interest statement}

There are no potential conflicts of interest or any financial or personal relationships with other people or organizations that could inappropriately bias conduct and findings of this study.

Submitted on invitation.

Accepted on 24 September 2012. 


\section{References}

1. World Health Organization. Calcium and magnesium in drinking-water. Public health significance. Geneva: WHO; 2009.

2. World Health Organization. Guidelines for drinking-water quality. Fourth edition. Geneva: WHO; 2011.

3. Kah M, Levy L, Brown C. Potential for effects of land contamination on human health. 1 . The case of cadmium. $J$ Toxicol Environ Health B Crit Rev 2012;15(5):348-63. http://dx.doi.org/10.1080/10937404.2012.705107

4. FAO/WHO. Evaluation of certain food contaminants. Seventysecond report of the Joint FAO/WHO Expert Committee on Food Additives. Geneva: WHO; 2011. p. 21-37. (WHO Technical Report Series 959. Arsenic).

5. Fawell J, Bailey K, Chilton J, Dahi E, Fewtrell L, Magara Y. Fluoride in drinking-water. Geneva: WHO; 2006.

6. Gore F, Fawell JK, Bartram J. Too much or too little? A review of the conundrum of selenium. Water Health 2009;8(3):405-16.

http://dx.doi.org/10.2166/wh.2009.060

7. World Health Organization. Uranium in Drinking-water. Background document for the development of the Guidelines for drinking-water quality. Geneva: WHO; 2012. Available from: http://www.who.int/water_sanitation_health/publications/2012/background_uranium.pdf.

8. Chorus I, Bartram J (Eds). Toxic cyanobacteria in water. A guide to their public health consequences, monitoring and management. London \& New York: E \& FN Spon; 1999.

9. Erdner DL, Dyble J, Parsons ML, Stevens RC, Hubbard KA, Wrabel ML, Moore SK, Lefebvre KA, Anderson DM, Bienfang P, Bidigare RR, Parker MS, Moeller P, Brand LE, Trainer VL. Centers for oceans and human health: a unified approach to the challenge of harmful algal blooms. Env Health 2008;7(Suppl. 2)7:S2.

10. World Health Organization. Nitrate and nitrite in drinking-water: Background document for the development of the WHO guidelines for drinking-water quality. Geneva: WHO; 2012. http://dx.doi.org/10.1186/1476-069X-7-S2-S2

11. Bryan NS, Loscalzo J (Eds). Nitrate and nitrite in human health and disease. New York: Humana Press; 2011. http://dx.doi.org/10.1007/978-1-60761-616-0

12. FAO/WHO. Evaluation of certain food contaminants. Sixtyfirst report of the Joint FAO/WHO Expert Committee on Food Additives. Methylmercury. Geneva: WHO; 2004. (WHO Technical Report, Series 922).

13. Judd N, Griffith WC, Faustman EM. Contribution of PCB exposure from fish consumption to total dioxin-like dietary exposure. Reg Toxicol Pharmacol 2004;40(2):125-35. http://dx.doi.org/10.1016/j.yrtph.2004.06.004

14. Shaw SD, Kannan K. Ocean pollution: Health and environmental health impacts of brominated flame retardants. In: Selendy JMH (Ed). Water and sanitation-related diseases and the environment. Challenges, interventions and preventive measures. Hoboken, USA: Wiley-Blackwell; 2011. http://dx.doi.org/10.1002/9781118148594.ch34

15. UK Drinking Water Inspectorate. Guidance on the water supply (water quality) Regulations $2000^{I}$ specific to PFOS (perfluorooctane sulphonate) and PFOA (perfluorooctanoic acid) concentrations in drinking water. London: Drinking Water Inspectorate; 2009. Available from: http://dwi.defra.gov.uk/ stakeholders/information-letters/2009/10_2009annex.pdf.

16. European Food Standards Agency. Perfluoroalkylated substances in food: occurrence and dietary exposure. EFSA J 2012;10(6)2743:55.

http://dx.doi.org/10.2903/j.efsa.2012.2743

17. Fawell JK. The role of toxicology. In: Lack T (Ed). Environmental protection standards compliance and costs. New York: Ellis Horwood; 1983.

18. Fawell JK, Sheahan D, James HA, Hurst M, Scott S. Assessment of oestrogens and oestrogenic activity in raw and treated water in severn trent water. Water Res 2001;35(5):1240-4 http://dx.doi.org/10.1016/S0043-1354(00)00367-5

19. Wenzel A, Müller J, Ternes T. Study on endocrine disrupters in drinking water. Schmallenberg and Wiesbaden: European Commission; 2003. (Final Report ENV.D.1/ETU/2000/008). Available from: http://ec.europa.eu/research/endocrine/pdf/ drinking_water_en.pdf.

20. Watts C, Maycock D, Crane M, Fawell J, Goslan E. Desk based review of current knowledge of pharmaceuticals in drinking water and estimation of potential levels. Watts and Crane Associates; 2007. (Final Report to DWI). Available from: http://dwi.defra.gov.uk/research/completed-research/ reports/dwi70-2-213.pdf.

21. Bull RJ, Crook J, Whitaker M, Cotruvo J. Therapeutic dose as the point of departure in assessing potential health hazards from drugs in drinking water and recycled municipal wastewater. Reg Tox and Pharm 2011;60:1-19. http://dx.doi.org/10.1016/j.yrtph.2009.12.010

22. World Health Organization. Pharmaceuticals in drinking-water. Geneva: WHO; 2011

23. Boxall ABA, Monteiro SC, Fussell R, Williams RJ, Bruemer J, Greenwood R, Bersuder P. Targeted monitoring for human pharmaceuticals in vulnerable source and final waters. Drinking Water Inspectorate Project No WD0805 (Ref DWI 70/2/231). 2011. Available from: http://dwi.defra.gov. uk/research/completed-research/reports/DWI70_2_231.pdf.

24. Fawell J, Ong CN. Emerging contaminants and the implications for drinking water. Int J Water Res Dev 2012;28(2):247-64. http://dx.doi.org/10.1080/07900627.2012.672394

25. Hrudey SE, Charrois JWA (Eds). Disinfection by-products and human health. London: IWA Publishing; 2012.

26. Toledano MB, Nieuwenhuijsen MJ, Best N, Whitaker H, Hambly P, de Hoogh C, Fawell J, Jarup L, Elliott P. Relation of trihalomethane concentrations in public water supplies to still birth and birth weight in three water regions in England. Environl Health Perspect 2005;113:225-32.

http://dx.doi.org/10.1289/ehp.7111

27. FAO/WHO. Evaluation of certain food contaminants. Sixtyseventh meeting of the Joint FAO/WHO Expert Committee on Food Additives. WHO Food additives series 58. Aluminium from all sources including food additives (Addendum). Geneva: WHO; 2007. p. 119-207.

28. Centers for Disease Control and Prevention. Lead. Available from: http://www.cdc.gov/nceh/lead/. Viewed September 2012.

29. World Health Organization. Copper in drinking-water. Background document for development of WHO Guidelines for drinking-water quality. Geneva: WHO; 2004. Available from: http://www.who.int/ water_sanitation_health/dwq/chemicals/copper.pdf.

30. Zietz BP, de Vergara JD, Dunkelberg H. Copper concentrations in tap water and possible effects on infant's health results of a study in Lower Saxony, Germany. Environ Res 2003;92(2):129-38 http://dx.doi.org/10.1016/S0013-9351(03)00037-9 